Submission ID: 43849

\title{
Special Aspects of Complex Reservoirs Interpretation on the Example of
}

Pannonian Basin

E.F. Tcukanova* (NIS NTC), K.A. Ezhov (NIS NTC), E.S. Milei (NIS NTC)

\section{SUMMARY}

The main objectives of this work is to prepare complex petrophysical and geological model for complex reservoirs: heterogeneous sandstones-conglomerates and naturally fractured metamorphic basement. Each case is very actual not only for local experience but for the global understanding: number of objects with the complexity is increasing, that means the time of pure and clear sandstones has passed. We need to develop and use new approaches, based on more advanced tools and interpretation techniques. 
Особенности изучения и интерпретации сложнопостроенных коллекторов Паннонского бассейна.

Авторы доклада. Е.Ф. Цуканова*(НИС НТЦ), К.А. Ежов*(НИС НТЦ), Е.С. Милей*(НИС НТЦ)

\section{Введение}

Несмотря на развитие возобновляемой энергетики, еще долгие годы углеводородное топливо будет востребованным. Сегодня уже кончается время легких месторождений, вместе с тем продолжается поиск новых месторождений и новых решений для работы с разведанными, но с трудноизвлекаемыми запасами.

В своем большинстве, вновь открытые месторождения это суперсложные обьекты, где не работают принятые и традиционные методики интерпретации данных ГИС и исследований на керне, но по прежнему существует необходимость качественной оценки запасов и прогноза добычи углеводородов.

Этот вопрос стоит остро для всех нефтегазодобывающих стран. В работе речь пойдет месторождениях Сербии и о применяемых подходах, методиках и методах ГИС.

Следует отметить, что на территории Сербии к сложным объектам относятся все, без исключения месторождения, учитывая присутствие сложной тектоники.

К объектам исследования относятся коллектора различного происхождения и уровня сложности: слабоконсолидированные песчаники, неоднородные по текстуре конгломераты, тектонически дислоцированные и эродированные брекчии, трещиноватые породы кристаллического фундамента и т.д.

Каждый объект представляет собой промышленный интерес с точки зрения углеводородного потенциала и научную новизну в плане использованных подходов и методов при работе с ним. В представленной работе мы коснемся подробно только некоторых объектов, а именно коллекторов конгломератов на примере нового месторождения и трещиноватых пород фундамента месторождения, которое уже находится в разработке.

\section{Метод}

На вновь открытом месторождении в 2016 г. пробурены последовательно две разведочные скважины с отбором керна, которые приурочены к разным тектоническим блокам и представлены различными типами пород в пределах продуктивного пласта Баден (Bd) , залегающего на глубине 2200 м (рис.1).

Нами разработана программа исследований на керне, в том числе и полноразмерном, в зависимости от типа пород. Выявлены и обоснованы грубые погрешности керновых исследований для пород, представленных конгломератами и песчаниками с содержанием минералов пирита (рис.2). Главным образом, погрешности касаются измерений удельного электрического сопротивления с целью обоснования параметров уравнений Арчи-Дахнова.

Исследования УЭС на керне признаны неэффективными на образцах конгломератов и образцах песчаника с содержанием пирита, поэтому были забракованы; электрическая модель насыщенности, полученная на керне полностью противоречила фактическим данным по скважине. С методической точки зрения исследования проведены корректно, но без организации мероприятий учета неоднородности, они не могут быть использованы для моделирования. Учесть же с высокой точностью неоднородность, к примеру внутри образца конгломерата, задача непростая. 


\section{EAGE}

EUROPEAN ASSOCIATION OF
GEOSCIENTISTS \& ENGINEERS

\section{就 Геомодель-2017}

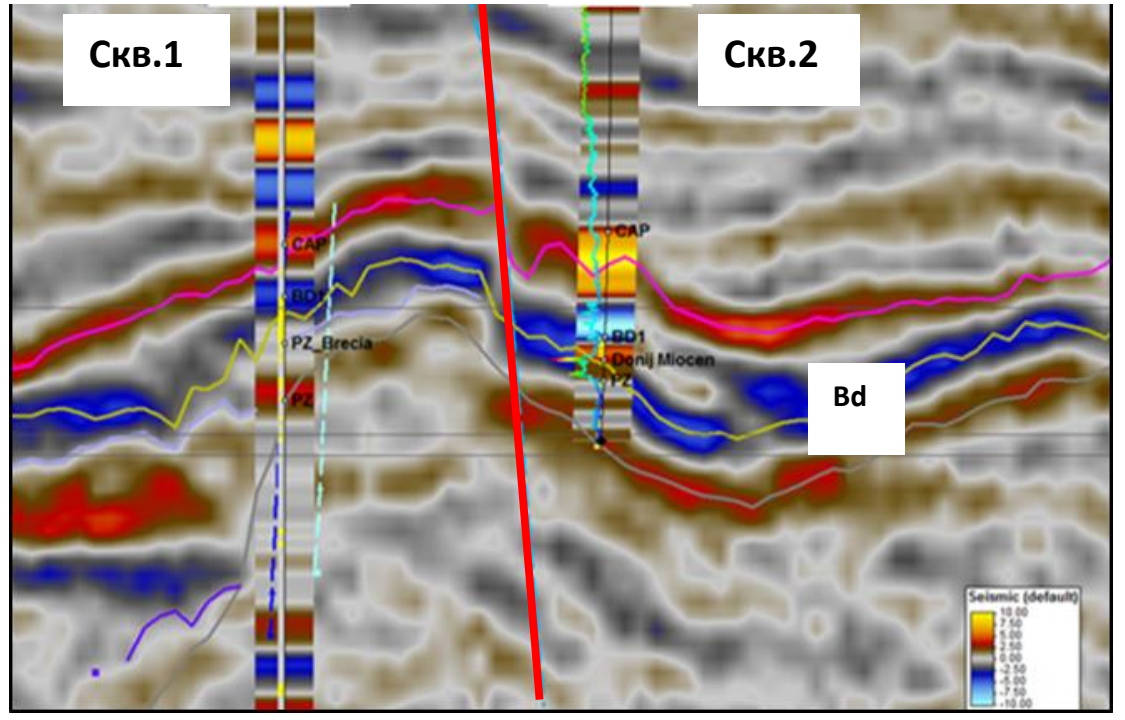

Рисунок 1 Временной сейсмический разрез через скважины 1 и 2

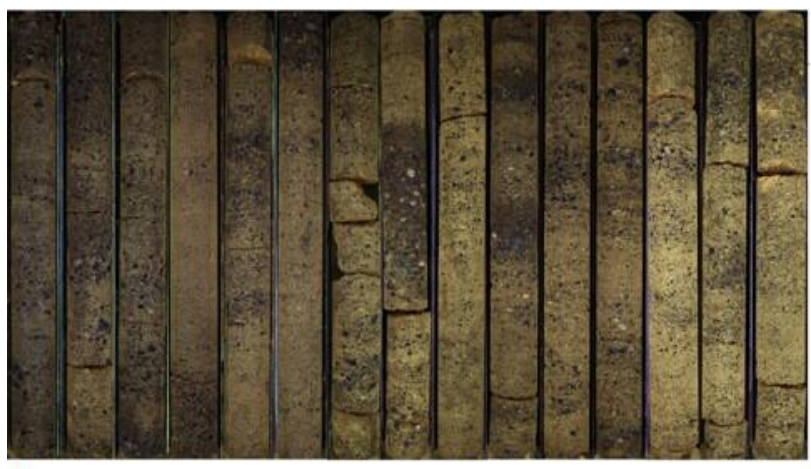

ᄂ

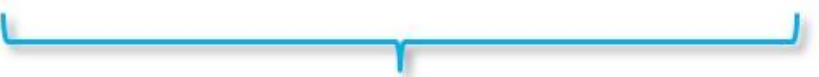

Мелкорбломочный конгломерат

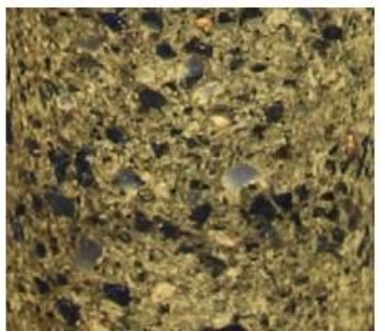

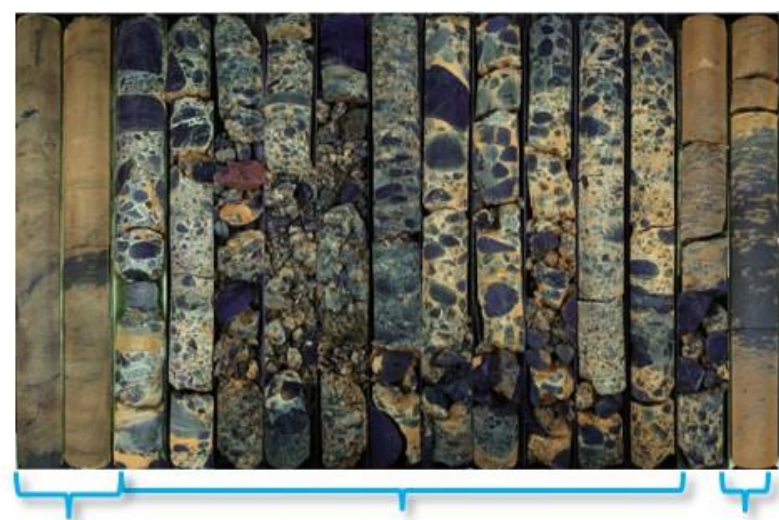

Песчаник с включениями углей и пирита

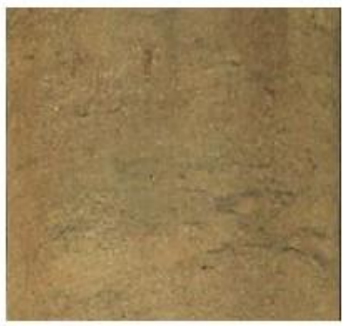

Песчаник с включениями углей и пирита

Рисунок 2 Фото нефтенасыщенного керна в ультрофиолетовом свете по скважинам 1 и 2 u литотипь

В связи с этим была создана капиллярная модель насыщенности, на основе функции Томира и настроена на фактическую добычу, после чего на поученные результаты настроена и электрическая модель, что позволяет ее применять на новых скважинах 


\section{EAGE

Как показало бурение скважины №2, капиллярную модель насыщенности нельзя применить по причине приуроченности скважины к другому блоку и другой фациальной обстановке, поэтому для этого блока создана отдельная капиллярная модель насыщенности.

Это касается и зависимостей для прогноза проницаемости, по результатам исследований проведена типизация пород с привлечением данных микросканера и настроены отдельные зависимости для оценки проницаемости по типам пород.

Ниже пласта $\mathrm{Bd}$ повсеместно не территории Сербии залегают породы палеозойского фундамента, представленные, в основном, метаморфизованными кристаллическими сланцами. Залежи нефти в интервалах палеозойского фундамента приурочены, преимущественно, к трещиноватым коллекторам.

Трещиноватые коллекторы, в том числе и в интервалах фундамента, широко распространены по всему миру - промышленная добыча ведется более чем в 30 странах, но и по сей день успешное бурение, выделение продуктивных объектов, оценка их свойств и запасов актуальная задача. Не существует методики выделения продуктивных зон и свойств стандартными методами, необходимо изучать индивидуально каждое месторождение, искать закономерности, подходы, калибруясь на результат.

В настоящей работе представлен наш опыт комплексного подхода к интерпретации таких коллекторов. Последовательно оценивая важность и бесполезность специального каротажа, керновых исследований и методик интерпретации на месторождении Турия, были созданы алгоритмы интерпретации данных ГИС и выделения перспективных интервалов для перфорации и ГРП.

На первом этапе мы научились обрабатывать и интерпретировать данные микросканеров подрядных организаций, оценивая качество записи в день ее проведения. На месторождении Турия встречаются всевозможные текстурные и структурные элементы и их комбинации (рис.3).

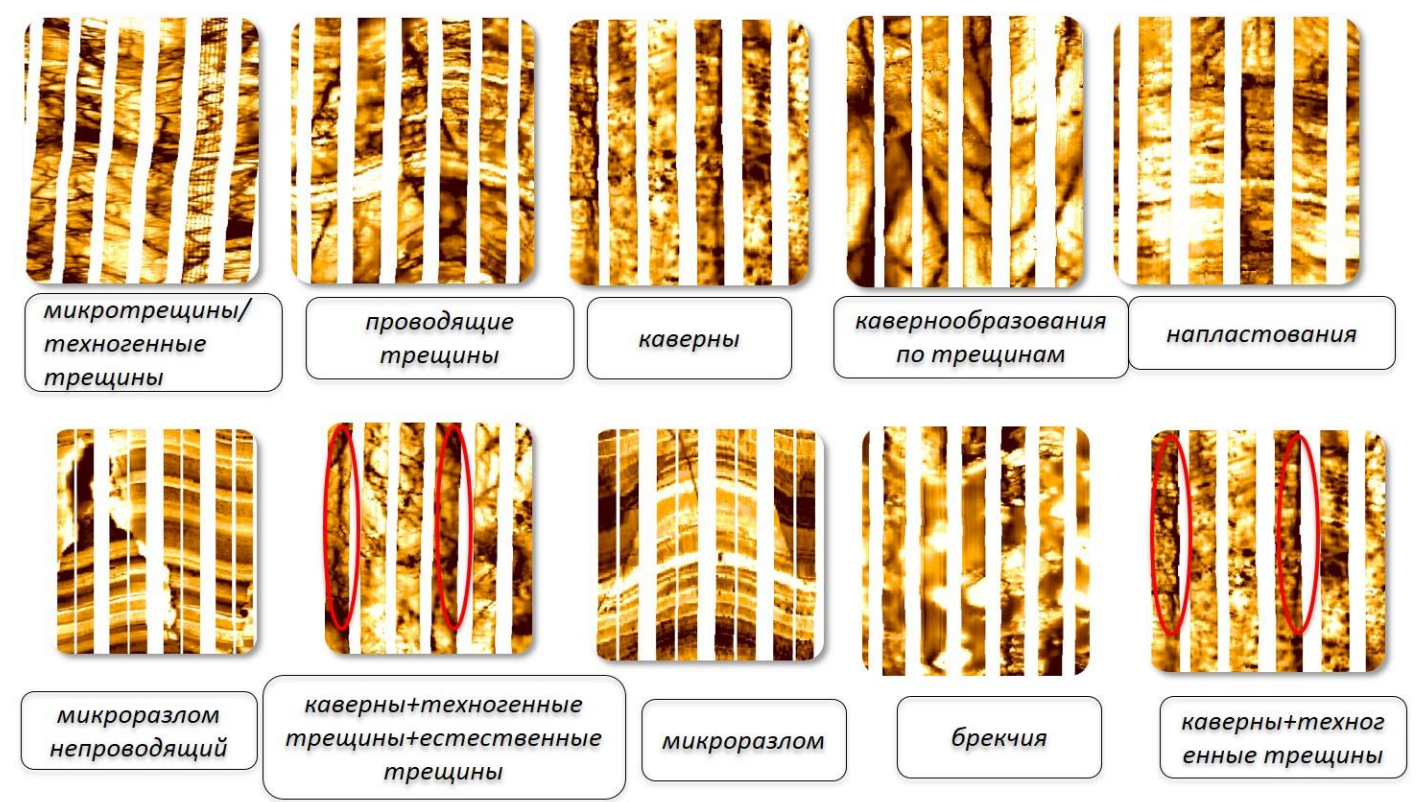

Рисунок 3 Примеры выделяемых элементов в изучаемых отложений 
Далее в нескольких скважинах, в качестве эксперимента, проведен ядерно-магнитный каротаж (ЯМК), так как разрез частично представлен смешанным типом пустотного пространства. Результаты были использованы для калибровки и настройки прогноза наличия емкостного пространства по объемной минералогической модели. Коэффициент пористости, рассчитывамый в результате объемной минералогической модели с высокой точностью коррелируется с коэффициентом пористости по ЯМК, что позволяет прогнозировать наличие емкостных интервалов и не записывать дорогостоящий ЯМК, не являющий эффективным в данном типе разреза из -за ограничений метода.

На следующем этапе проведен расчет хрупкости двумя способами. Совместный анализ изменения хрупкости, наличия емкости и данных объемной минералогической модели позволяет корректно определять перспективные интервалы испытаний, а также сворачивать эту информацию в макротипы разреза для целей геологического моделирования.

Одним из способов снижения рисков на этапе изучения и разработки подобных отложений является построение геомеханической модели. Она снижает риск разрушения ствола скважины в процессе бурения - обычное явление в интервалах брекчированных и хрупких пород, а также повышает эффективность проведения ГРП за счет учета хрупкости отложений и пространственной ориентации стрессов. Среди необходимой информации отдельно следует выделить результаты лабораторных исследований: именно они являются критерием достоверности при изучении упругих и прочностных свойств горной породы. В нашей работе подробно представлена примененная схема, сочетающая в себе петрофизические и механические исследования. Задача петрофизика максимально профессионально подойти к планированию и подготовке этих данных.

\section{Выводы}

При работе со сложными коллекторами, Паннонского бассейна рассмотрены и предложены:

- оптимальный комплекс ГИС

- исследования на керне, в том числе для целей построения геомеханической модели

- расчет водонасыщенности в конгломератах

- методика восстановления емкостных интервалов в трещиноватых коллекторах

- методика совместного анализа хрупкости, объемной минералогической модели и наличия емкостных интервалов для выявления продуктивных зон в продуктивных отложениях фундамента

Оптимизация комплекса исследований и применение нестандартных подходов может существенно снизить неопределенность на этапе планирования новых скважин, выборе интервалов испытаний и подсчета запасов углеводородов.

\section{Библиография / References}

Aguilera, R. (1995c). Naturally Fractured Reservoirs (Second Ed.). Pennwell, Tulsa, OK, USA, pp.447-448. 